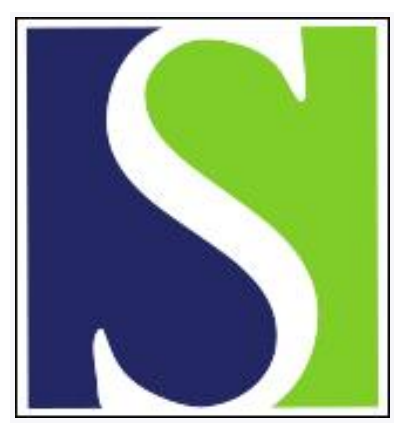

Scand J Work Environ Health 1996;22(4):294-305

https://doi.org/10.5271/sjweh.144

Issue date: Aug 1996

Job strain and ambulatory blood pressure levels in a population-based employed sample of men in northern Italy by Cesana G, Ferrario M, Sega R, Milesi C, De Vito G, Mancia G, Zanchetti A

The following article refers to this text: 2014;40(2):109-132

Key terms: coronary risk; epidemiology; work stress

This article in PubMed: www.ncbi.nlm.nih.gov/pubmed/8881018

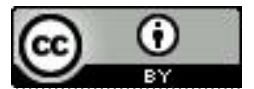




\title{
Job strain and ambulatory blood pressure levels in a population-based employed sample of men from northern Italy
}

\author{
by Giancarlo Cesana, MD, ${ }^{1}$ Marco Ferrario, MD, ${ }^{1,2}$ Roberto Sega, MD, ${ }^{1}$ Camilla Milesi, MS, ${ }^{1}$ \\ Giovanni De Vito, MD, ${ }^{2}$ Giuseppe Mancia, MD, ${ }^{3}$ Alberto Zanchetti, $M D^{3}$
}

\begin{abstract}
Cesana G, Ferrario M, Sega R, Milesi C, De Vito G, Mancia G, Zanchetti A. Job strain and ambulatory blood pressure levels in a population-based employed sample of men from northern Italy. Scand $J$ Work Environ Health 1996;22:294-305
\end{abstract} Objectives The purpose of this cross-sectional study was to examine the associations between categories of
perceived job strain and blood pressure, measured by clinical and ambulatory devices on a population-based
sample of employed men in northern Italy.
Methods The study included 527 employed normotensive or mild hypertensive nonmedicated men enrolled in
an age-gender stratified random sample of 82125 - to 64 -year-old residents of the city of Monza (in the vicinity
of Milan). The job-strain categories were classified according to the traditional quadrant-term approach and also
a new approach based on the comparison of extreme tertile categories in order to enhance contrasts. Clinical
blood pressure was measured according to the standardized MONICA procedure; 24 -h, work, leisure, and
nighttime blood pressure values were obtained with an ambulatory device. Disparities, calculated as differences
between clinical and ambulatory measurements, were also analyzed.
Results Among normotensive working men the highest mean for systolic blood pressure was found in the
high-strain group, and progressively lower values were found in the passive, active and low-strain categories.
These patterns were observed for both the clinical and ambulatory measurements. Among the mild hypertensive
subjects, lower mean values for ambulatory systolic and diastolic blood pressure were found in the passive and
high job-strain categories when the tertile term approach was adopted. The passive group also showed the
highest mean difference between the clinical and ambulatory measurements; this finding indicates that they may
be more susceptible to alarm reactions.
Conclusions The results indicate that job strain affects blood pressure in population-based samples and the effect is consistent across sociocultural contexts.

Key terms coronary risk, epidemiology, work stress.

The assessment of the relationship between stress at work and coronary risk is the subject of ongoing investigation. An extensive review of the epidemiologic literature, published in 1989, emphasized that, of several nonchemical factors in the work environment, job organization is one of the better documented hazards (1). This review found considerably more positive evidence than did earlier ones. Research in the field has been significantly expanded and improved, due to the availability of standardized measurement tools. Among these, several editions of the questionnaire implemented by Karasek \& Theorell (2) have gained popularity for the simplicity and adequacy of their model, which evaluates the balance be- tween demands and control at work. Recently a few questions on a third dimension concerning social relations at work have been added (3).

The demand-control hypothesis, as originally proposed by Karasek (4), has been tested in several crosssectional, case-referent and cohort studies through two basically different methods, a "direct" method, which relies on subjects' own descriptions of their work situation, and an "indirect" method, which relies on aggregate job-description data based on workers representative of the occupations in the populations (5).

Major outcomes of epidemiologic research are promising, even if their theoretical and methodological

1 Research Centre on Chronic-Degenerative Diseases, University of Milan, Monza, Italy.

2 Institute of Occupational Health, University of Milan, Milan, Italy.

3 Centro Studi Fisiologia Clinica e Ipertensione, University of Milan, Milan, Italy.

Reprint requests to: Professor Giancarlo Cesana, Centro Studi Patologia Cronico Degenerativa, Università di Milano Ospedale Nuovo 'San Gerardo', Villa Serena VI piano, Via Donizetti 106, I-20052 Monza, Italy. 
premises are not fully satisfying (6). Many positive associations have been observed between job strain (measured using both direct and indirect methods) and cardiovascular morbidity and mortality $(7-12)$. On the other hand, no positive associations have been found in two incidence studies $(13,14)$ on in a prevalence study of employed patients undergoing coronary angiography (15). Relevant data have also been reported regarding the association between job strain and major coronary risk factors, namely, blood pressure measured in a clinical setting $(14,16-21)$, serum cholesterol $(14,18,19)$, and smoking $(14,18,19,22)$.

The inclusion of an ambulatory measuring criterion seems to make the association between job strain and blood pressure stronger. Of 12 studies in which ambulatory blood pressure (ABP) measurements were performed, seven reported significant positive results (23$29)$, while the remaining five provided mixed results (30-34). These findings suggest a consistent causal relationship between job strain and rise in blood pressure; they were obtained in samples that differ in number, blood pressure levels, gender, and work characteristics, even if not representative of the general working population.

A standard edition of the Karasek questionnaire has been included among the "suggested measurement instruments" of the psychosocial optional study - named MOPSY (MOnica PSYchosocial) (35) - of the WHO MONICA project (36). This is a 10 -year program for MONItoring CArdiovascular diseases, involving 39 centers all over the world. Several centers, including Area Brianza in Italy, adhered to MOPSY and adopted the proposed instruments in periodic population surveys.

The Italian version of the MOPSY job-strain questionnaire was introduced in the form of a pilot study during the first Area Brianza MONICA survey in 1986. After carrying out minor modifications in wording, to improve the understanding of some questions by less educated subjects, and assessing the internal consistency, the questionnaire was used in its final edition (37) in the subsequent MONICA surveys and in an ancillary study focusing on ambulatory blood pressure normalcy, named PAMELA, in 1990-1991 (38). Results of this latest study are reported in this communication.

The purpose of the presented cross-sectional study was to examine the associations between perceived jobstrain categories and levels of blood pressure, measured by clinical and ambulatory devices on a randomized, population-based sample of employed men in northern Italy. They represent a sociocultural context that differs from that of the United States and northern Europe, where the Karasek-Theorell paradigm was born and repeatedly verified. Moreover, since the investigation of the relationship between job strain and ambulatory blood pressure devoted particular attention to borderline and mild hypertensives $(23,24,26,28,34)$, in this report different analyses were also performed, separately, on normotensive and mild hypertensive subjects, to evaluate the homogeneity of the results and possible selection biases among job-strain categories based on the definition of hypertension. Finally, since several alternative formulations of job strain have been proposed recently (29), in addition to the traditional approach, a new formulation was adopted in the present analysis to identify job-strain categories while enhancing the contrasts between them.

\section{Subjects and methods}

The procedures used in the PAMELA study for sampling subjects and assessing coronary risk and psychosocial factors were identical to the ones developed for the MONICA project (38). In addition, each subject underwent a 24-h ABP measurement.

\section{Characteristics of the population and the sample}

The PAMELA sample was drawn from the electoral rolls of the city of Monza, the major town (about 200000 inhabitants) in Area Brianza. Electoral rolls are automatically generated from the anagraphic list of the Italian citizens who are residents; they are frequently updated because administrative and political elections have occurred often in the last 10 years. Area Brianza is a highly industrialized district situated between Milan and the Swiss border. In particular, the city of Monza is characterized by industrial, commercial, and administrative activities. In this area cardiovascular and coronary mortality rates, as well as related risk factor prevalence, have been decreasing in the last 10 years (39).

As the primary objective of the PAMELA study focused on assessing ambulatory reference values for blood pressure measurement, a gender- and age-stratified random sample was selected from the 25- to 64-year-old residents of the town. About 300 subjects were identified in each age decade. Due to the high rate of unemployment among women (55\%), for the purpose of the present analysis, only men were considered. Of the 1182 eligible men, 821 were enrolled in the study, corresponding to an overall participation rate of $69.5 \%$, with small fluctuations among the age strata. About $80 \%$ of the nonrespondents were interviewed by phone, and there was no evidence of self-selection processes, when sociodemographic features, hypertension awareness, and treatment were taken into consideration.

The analysis was restricted to the 635 currently employed men ( $77 \%$ of the enrolled male sample). Moreover, hypertensive subjects under drug treatment $(\mathrm{N}=50)$ or with very high clinical blood pressure (CBP) 


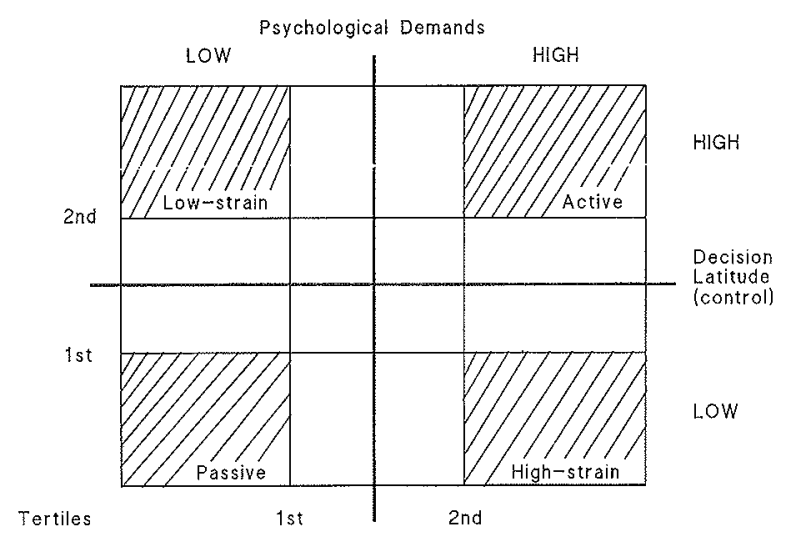

Figure 1. Karasek job-strain model: quadrant and (dashed) tertile term scoring areas.

values [systolic $\geq 165 \mathrm{~mm} \mathrm{Hg}(21.9 \mathrm{kPa})$ or diastolic $\geq 100 \mathrm{~mm} \mathrm{Hg}(13.3 \mathrm{kPa}) \mathrm{N}=30$ ], as well as subjects who were missing values for ABP measurements $(\mathrm{N}=4)$ or who did not completely fill out the job-strain questionnaire $(\mathrm{N}=24)$ were excluded. The final available sample size was 527 subjects.

\section{Job-strain assessment}

In the course of several MONICA psychosocial meetings, coordinated by the WHO Regional Office for Europe in Copenhagen, the scales and scoring criteria adopted by the centers adhering to MOPSY were periodically revised and the scales were adapted to different sociocultural contexts. Translations and back-translations were performed and new editions of an operation manual were produced. The MOPSY questionnaire, adopted in the PAMELA survey, contains a short version of the Karasek scale, composed of 13 items, of which the six on decision latitude and the five on job demands were considered and scored (40). No questions on social support at work were included in the questionnaire.

As stated in the Introduction section, two separate but similar models for defining job-strain categories were used. The first, most commonly accepted, defines four groups using the sample medians of each score of the two considered dimensions as cut points. Persons assigned to the high-strain group were those who scored above the sample median of the demand scale and equal to or below the median of the decision latitude scale. Similarly, the passive condition was determined by demand and decision scores equal to or below the corresponding sample medians, the active condition was derived from scores above the median for both dimensions, and the low-strain condition was formed by levels of job demand equal to or below the median and decision latitude above the median. In a recent publication this approach was called the quadrant term (29).

The advantage of the quadrant term is that it is a powerful model that uses all available degrees of free- dom. However, a relevant portion of persons who attain intermediate scores are classified into different job-strain categories even if the score values do not clearly differ. To enhance the contrasts between the job-strain categories, we propose a new model. In this tertile-term model, job-strain categories are identified only for subjects whose scores exceed the tertiles of the bivariate distribution of latitude and demand dimensions (figure 1). According to this approach, individuals are assigned to the new high-strain category if they score above the higher tertile on the demand scale and equal to or below the lower tertile on the decision-latitude scale. The remaining three job-strain categories are determined according to analogous criteria. Due to the relatively small range and skewness of the two partial score distributions, the tertile and the median cut points overlap occasionally.

\section{Survey procedures}

The detailed procedures adopted in the PAMELA study have been described elsewhere (38). A brief review of the methods to assess relevant parameters follows. Each participant underwent a clinical examination that included collection of a comprehensive and standardized medical history (including education and cigarette smoking); measurement of weight, height, standard blood pressure and pulse; and blood drawing for lipid determinations. The Italian version of the MOPSY questionnaire was administered before the medical visit. It contained, in addition to the job-strain scale, other scales suggested by MOPSY (social mobility, vital exhaustion, social support, type A), a short scale evaluating habitual physical activity during work and leisure time (41), and nine items relating to work conditions.

The CBP measurements were taken twice, $10 \mathrm{~min}$ apart, by trained physicians on subjects in a sitting position, after $10 \mathrm{~min}$ of rest and at least $1 \mathrm{~h}$ from venipuncture. A standard sphygmomanometer was used, recording the $\mathrm{V}$ phase of the Korotkoff sounds as the diastolic value according to the standardized procedure adopted in the MONICA project (42). The average of the two measures was used as a study variable.

For the purposes of the present analysis, the subjects were classified as borderline-mild hypertensives when the systolic blood pressure values were between 140 and $165 \mathrm{~mm} \mathrm{Hg}$ (18.62 and $21.9 \mathrm{kPa}$ ) or the diastolic values were between 90 and $100 \mathrm{~mm} \mathrm{Hg}$ (12.0 and $13.3 \mathrm{kPa}$ ). The following sociodemographic characteristics were collected on each individual: age, as the difference between the date of examination and the date of birth; education, scored in two classes, compulsory (up to eight years of full-time schooling) and more than compulsory; and occupational level, categorized into the five groups of executives (managers, professionals), small business owners, clerks, skilled manual workers, and unskilled manual workers. 


\section{Ambulatory blood pressure measurement}

The oscillometric SpaceLabs 90207 equipment (SpaceLabs, Redmont, Washington, United States) was used for the ambulatory monitoring of blood pressure, It was applied at the end of the medical visit according to a standardized procedure (43). The cuff was fixed to the nondominant arm with tape and three blood pressure readings were taken concomitantly by a standard sphygmomanometer to ensure that the average of two sets of values did not differ by more than $5 \mathrm{~mm} \mathrm{Hg}(0.67 \mathrm{kPa})$. Then the device was set to obtain automatic blood pressure recordings at 20 -min intervals for $24 \mathrm{~h}$. The participants were instructed to hold the arm immobile and extended during the measurement time, which was signaled by a buzzer and lasted for about $1 \mathrm{~min}$. The recording was always planned for a workday (Monday to Friday) while the subject performed his usual activity (when on rotating shifts he was asked to participate when on the morning shift). The participant had no access to the ABP readings. Each of the 12 ABP monitoring devices available was checked monthly by obtaining 10 automatic and 10 auscultatory blood pressure readings simultaneously from the same arm, via a $Y$ tube. In all instances, the values did not differ by more than $5 \mathrm{~mm} \mathrm{Hg}(0.67 \mathrm{kPa})$.

The following parameters were computed for both systolic and diastolic blood pressure: the 24-h ambulatory (24-h ABP) mean, the work-time mean (work $A B P$ ) from 0700 to 1659 , the leisure-time mean from 1700 to 2359 , and the nighttime mean from 0000 to 0659 .

\section{Statistical analysis}

According to the formulations of job strain, the median cut-point values for ranking the quadrant-term categories were 12 and 18 for the job-demand and the job-latitude scores, respectively. For the tertile term, the cut points were 12,13 and 18,19 .

Possible differences in the distributions of the normotensives and mild hypertensives in the educational classes, occupational levels, and job-strain categories (quadrant and tertile terms) were assessed using the chisquare test. Similarly, to assess differences in age and in the CBP and $\mathrm{ABP}$ values between normotensives and mild hypertensives, the Student's t-test was applied.

The systolic and diastolic blood pressure values obtained by clinical and ambulatory measurements were considered separately as dependent variables in the analysis of covariance models, using the SAS general linear model procedure (44), and the explanatory variables were the job strain categories (quadrant or tertile terms). In each model the following covariates were included as fixed effects: age, educational class, an overweight index (normo-weight versus overweight, classified according to body mass index, as the ratio between weight in kilograms and squared height in meters, at the cut-off value of 25), and a work physical-activity index (sedentary versus nonsedentary job). Occupational level was not included as a covariate because its statistical contribution was irrelevant after education and physical activity were included. As a second step, first-order interaction terms were also added to all the models. Since neither statistically significant effects of the interaction terms nor relevant improvements in the R-square (of the covariance models) were detected for any of the interaction terms, they were no longer kept in the models. Separate models were fitted for the entire sample, for the normotensives and for the mild hypertensives.

Finally, differences or disparities between the CBP and (minus) 24-h ABP and between the CBP and (minus) work $A B P$ values were computed. They can be considered an expression of individual responsiveness, which normalizes when longer periods of blood pressure monitoring are evaluated (45), or as an expression of methodological problems, for example, sampling scheme, procedure used for the CBP measurements, or intraindividual blood pressure variations. Differences in the blood pressure disparities among the job-strain categories (quadrant and tertile term) and the blood pressure classes (normotensive and mild hypertensive) were analyzed with twoway analysis of variance models, the covariates being age, education, and the overweight index. In all the models, the first-order interaction terms between the job-strain categories and the blood pressure classes were also added. Separate models were fitted for the diastolic and systolic measures.

\section{Results}

The age group distributions of the employed sample in comparison with unemployed subjects in the PAMELA study are shown in table 1 . Working subjects were predominant in the young and middle-age classes. (This phenomenon is related to the age of retirement in Italy.) The difference in the age distributions in the two groups affects the percentage of hypertensive subjects, either treated or not (12.6\% in the employed group and $31.2 \%$ in the unemployed group). Applying exclusion criteria, based on high blood pressure values, hypertension treatment, and missing values, did not change substantially the age class distribution in the studied sample, originally randomized from a northern Italian male population. The prevalence of mild hypertension was $25.1 \%$.

As shown in table 2, no statistically significant differences in the distributions of the educational classes, occupational levels, and job-strain categories, adopting both quadrant- and tertile-term approaches, were detected between the normotensive and mild hypertensive 
workers. The tertile-term approach reduced the available sample size to 337 subjects [ie, of about one-third (36\%), less than expected $(56 \%)$, on the basis of the inclusion of the extremes exceeding the tertiles of a bivariate distribution]. This result occurred because, with the pro-

Table 1. Selection process and sample sizes in the PAMELA. $(\mathrm{SBP}=$ systolic blood pressure, $\mathrm{DBP}=$ diastolic blood pressure, $A B P=$ ambulatory blood pressure)

\begin{tabular}{|c|c|c|c|c|}
\hline & \multicolumn{2}{|c|}{ Employed } & \multicolumn{2}{|c|}{ Unemployed } \\
\hline & $\mathrm{N}$ & $\%$ & N & $\%$ \\
\hline $\begin{array}{l}\text { Originally enrolled subjects } \\
\text { Age group (years) }\end{array}$ & 635 & 100.0 & 186 & 100.0 \\
\hline $\begin{array}{l}25-34 \\
35-44 \\
45-54 \\
55-64\end{array}$ & $\begin{array}{r}182 \\
218 \\
173 \\
62\end{array}$ & $\begin{array}{r}28.7 \\
34.3 \\
27.5 \\
9.7\end{array}$ & $\begin{array}{r}14 \\
4 \\
34 \\
134\end{array}$ & $\begin{array}{r}7.4 \\
2.3 \\
18.3 \\
72.0\end{array}$ \\
\hline \multicolumn{5}{|l|}{ Exclusion for hypertension ${ }^{\mathrm{a}}$} \\
\hline $\begin{array}{l}\text { Treated } \\
\mathrm{SBP} \geq 165 \mathrm{mmHg} \text { or } \\
\mathrm{DBP} \geq 100 \mathrm{mmHg}\end{array}$ & $\begin{array}{l}50 \\
30\end{array}$ & $\begin{array}{l}8.0 \\
4.6\end{array}$ & $\begin{array}{l}36 \\
20\end{array}$ & $\begin{array}{l}19.4 \\
10.7\end{array}$ \\
\hline \multicolumn{5}{|l|}{ Exclusion for missing values } \\
\hline $\begin{array}{l}\text { ABP not recorded } \\
\text { Missing job-strain score }\end{array}$ & $\begin{array}{r}4 \\
24\end{array}$ & $\begin{array}{l}0.7 \\
4.3\end{array}$ & . & . \\
\hline $\begin{array}{l}\text { Sample size } \\
\text { Age groups (years) }\end{array}$ & 527 & 82.9 & . & . \\
\hline $\begin{array}{l}25-34 \\
35-44 \\
45-54 \\
55-64\end{array}$ & $\begin{array}{r}157 \\
182 \\
142 \\
46\end{array}$ & $\begin{array}{r}29.3 \\
34.5 \\
27.0 \\
8.7\end{array}$ & i. & $\dot{.}$ \\
\hline $\begin{array}{l}\text { Normotensives } \\
\text { Mild hypertensives }\end{array}$ & $\begin{array}{l}395 \\
132\end{array}$ & $\begin{array}{l}74.9 \\
25.1\end{array}$ & ; & . \\
\hline
\end{tabular}

a $1 \mathrm{mmHg} \approx 0.133 \mathrm{kPa}$. posed tertile-term approach, the job-strain categories were defined according to the cutoff points of the discrete distributions of the two scores (ie, decision latitude and job demand). For this reason, the numbers of subjects in the four job-strain categories were not precisely balanced.

Table 3 presents the mean values of age and blood pressure for the normotensive and mild hypertensive groups. The mild hypertensive subjects were older than the normotensives and, as expected, had higher CBP and ABP means. The difference in the CBP means [ 18 and $12.3 \mathrm{~mm} \mathrm{Hg}$ ( 2.4 and $1.6 \mathrm{kPa}$ ) for the systolic and the diastolic, respectively] were between two and three times higher than the difference in the ambulatory measurements, the work ABP differences being the closest $[8.5$ and $6.5 \mathrm{~mm} \mathrm{Hg}$ (1.1 and $0.9 \mathrm{kPa}$ ) for systolic and diastolic blood pressure, respectively]. This finding is due to the generally lower blood pressure values obtained by the ambulatory device in comparison with the clinical one, the only exception being the systolic and diastolic work ABP among the normotensives, which appeared to be higher or at least equal. Such contrasting findings may be partially explained as the effect of the regression to the mean (ie, lower ABP means among hypertensive subjects categorized by clinical measurement).

In tables 4 and 5 , the mean levels for the CBP, 24-h $\mathrm{ABP}$, and work ABP, blood pressure, adjusted for age, educational class, overweight, and work physical-activity indices, are reported for the job strain (quadrant-term and tertile-term categories). The data are presented separately for normotensive and mild hypertensive sub-

Table 2. Distribution of the normotensive and mild hypertensive subjects and the entire group of working men from the PAMELA general population sample according to education, occupational level and job strain categories, quadrant and tertile terms. (df $=$ degree of freedom, NS = not significant)

\begin{tabular}{|c|c|c|c|c|c|c|}
\hline & \multicolumn{2}{|c|}{ Normotensives } & \multicolumn{2}{|c|}{ Mild hypertensives } & \multicolumn{2}{|c|}{ Entire group } \\
\hline & $N$ & $\%$ & $N$ & $\%$ & $\mathrm{~N}$ & $\%$ \\
\hline \multicolumn{7}{|c|}{ Education (chi square, $1 \mathrm{df}=0.19, \mathrm{NS}$ ) } \\
\hline Compulsory school & 154 & 38.9 & 54 & 40.9 & 204 & 39.6 \\
\hline More than compulsory & 241 & 61.1 & 78 & 59.1 & 318 & 60.4 \\
\hline \multicolumn{7}{|c|}{ Occupational level (chi square, $4 \mathrm{df}=3.18, \mathrm{NS}$ ) } \\
\hline Executives & 105 & 26.6 & 32 & 24.2 & 137 & 26.0 \\
\hline Small business owners & 32 & 8.1 & 15 & 11.3 & 47 & 8.9 \\
\hline Clerks & 153 & 38.7 & 48 & 36.3 & 201 & 38.1 \\
\hline Skilled manual workers & 78 & 19.7 & 25 & 18.9 & 103 & 19.5 \\
\hline Unskilled manual workers & 27 & 6.9 & 12 & 9.3 & 39 & 7.5 \\
\hline \multicolumn{7}{|c|}{ Job strain, quadrant term (chi square, $3 \mathrm{df}=2.64, \mathrm{NS}$ ) } \\
\hline High strain & 70 & 17.7 & 17 & 12.9 & 87 & 16.6 \\
\hline Passive & 105 & 26.4 & 42 & 31.3 & 147 & 27.9 \\
\hline Active & 116 & 29.4 & 36 & 27.3 & 152 & 28.8 \\
\hline Low strain & 104 & 26.3 & 37 & 28.3 & 141 & 26.8 \\
\hline \multicolumn{7}{|c|}{ Job strain, tertile term (chi square, $3 \mathrm{df}=1.45, \mathrm{NS}$ ) } \\
\hline & 258 & & 79 & & 337 & \\
\hline High strain & 70 & 27.1 & 17 & 21.6 & 87 & 25.8 \\
\hline Passive & 62 & 24.0 & 19 & 24.0 & 81 & 24.0 \\
\hline Active & 76 & 29.5 & 28 & 35.4 & 104 & 30.9 \\
\hline Low strain & 50 & 19.4 & 15 & 19.0 & 65 & 19.3 \\
\hline
\end{tabular}

a Reduced sample sizes to 258 for the normotensives, 79 for the mild hypertensives, and 337 for the entire group. 
Table 3. Age and blood pressure (in $\mathrm{mm} \mathrm{Hg}^{\mathrm{a}}$ ) of the normotensive $(\mathrm{N}=395)$ and mildly hypertensive $(\mathrm{N}=132$ ) working men extracted from the PAMELA general population sample. ( $C B P=$ clinical blood pressure, $A B P=$ ambulatory blood pressure)

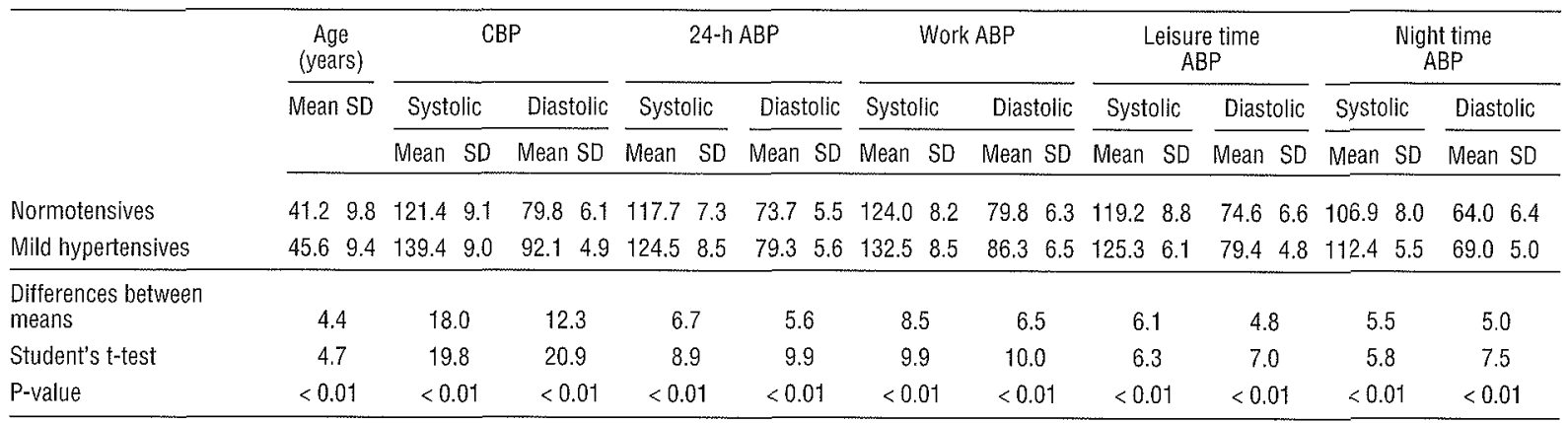

a $1 \mathrm{~mm} \mathrm{Hg} \approx 0.133 \mathrm{kPa}$.

Table 4. Mean systolic and diastolic blood pressures (adjusted for age, education, overweight index and physical-activity index) of the normotensive $(N=395)$ and mild hypertensive $(N=132)$ men and the entire group $(N=527)$ from the PAMELA general population sample according to the job-strain quadrant-term category. ( $C B P=$ clinic blood pressure, $A B P=$ ambulatory blood pressure)

\begin{tabular}{|c|c|c|c|c|c|c|}
\hline \multirow[t]{2}{*}{ Job-strain category } & \multicolumn{2}{|c|}{$\mathrm{CBP}\left(\mathrm{mm} \mathrm{H} \mathrm{g}^{\mathrm{a}}\right)$} & \multicolumn{2}{|c|}{ 24-h ABP $\left(\mathrm{mm} \mathrm{Hg}^{\mathrm{a}}\right)$} & \multicolumn{2}{|c|}{ Work ABP $\left(\mathrm{mm} \mathrm{Hg}^{\mathrm{a}}\right)$} \\
\hline & Systolic & Diastolic & Systolic & Diastolic & Systolic & Diastolic \\
\hline \multicolumn{7}{|l|}{ High } \\
\hline $\begin{array}{l}\text { Normotensives } \\
\text { Mild hypertensives } \\
\text { Entire group }\end{array}$ & $\begin{array}{l}124.5 \\
141.5 \\
127.8\end{array}$ & $\begin{array}{l}80.3 \\
90.0 \\
82.6\end{array}$ & $\begin{array}{l}119.7 \\
125.0 \\
120.8\end{array}$ & $\begin{array}{l}74.3 \\
78.3 \\
75.3\end{array}$ & $\begin{array}{l}126.2 \\
131.7 \\
127.4\end{array}$ & $\begin{array}{l}80.4 \\
84.4 \\
81.4\end{array}$ \\
\hline \multicolumn{7}{|l|}{ Passive } \\
\hline $\begin{array}{l}\text { Normotensives } \\
\text { Mild hypertensives } \\
\text { Entire group }\end{array}$ & $\begin{array}{l}122.8 \\
140.4 \\
127.6\end{array}$ & $\begin{array}{l}80.2 \\
91.5 \\
83.4\end{array}$ & $\begin{array}{l}118.1 \\
123.3 \\
119.5\end{array}$ & $\begin{array}{l}73.7 \\
78.1 \\
74.9\end{array}$ & $\begin{array}{l}125.0 \\
131.0 \\
126.6\end{array}$ & $\begin{array}{l}80.3 \\
84.9 \\
81.5\end{array}$ \\
\hline \multicolumn{7}{|l|}{ Active } \\
\hline $\begin{array}{l}\text { Normotensives } \\
\text { Mild hypertensives } \\
\text { Entire group }\end{array}$ & $\begin{array}{l}120.3 \\
138.1 \\
124.6\end{array}$ & $\begin{array}{l}80.2 \\
92.7 \\
83.3\end{array}$ & $\begin{array}{l}117.1 \\
124.6 \\
119.0\end{array}$ & $\begin{array}{l}73.8 \\
79.7 \\
73.3\end{array}$ & $\begin{array}{l}123.3 \\
133.8 \\
125.9\end{array}$ & $\begin{array}{l}79.8 \\
87.6 \\
81.7\end{array}$ \\
\hline \multicolumn{7}{|l|}{ Low } \\
\hline $\begin{array}{l}\text { Normotensives } \\
\text { Mild hypertensives } \\
\text { Entire group }\end{array}$ & $\begin{array}{l}120.2 \\
139.0 \\
124.6 \\
\end{array}$ & $\begin{array}{l}78.9 \\
92.1 \\
82.2 \\
\end{array}$ & $\begin{array}{l}116.9 \\
125.4 \\
119.0\end{array}$ & $\begin{array}{l}73.5 \\
80.2 \\
75.1 \\
\end{array}$ & $\begin{array}{l}122.8 \\
133.1 \\
125.3 \\
\end{array}$ & $\begin{array}{l}79.1 \\
87.2 \\
81.0 \\
\end{array}$ \\
\hline \multicolumn{7}{|l|}{$\overline{F p}$} \\
\hline $\begin{array}{l}\text { Normotensives } \\
\text { Mild hypertensives } \\
\text { Entire group }\end{array}$ & $\begin{array}{l}69.1^{\star \star \star} \\
0.7^{\star \star} \\
3.46^{\star \star}\end{array}$ & $\begin{array}{l}1.19 \\
1.19 \\
0.56\end{array}$ & $\begin{array}{l}2.97^{\star} \\
0.39 \\
1.15\end{array}$ & $\begin{array}{l}0.37 \\
1.16 \\
0.22\end{array}$ & $\begin{array}{l}3.03^{*} \\
0.61 \\
1.09\end{array}$ & $\begin{array}{l}0.93 \\
1.71 \\
0.31\end{array}$ \\
\hline
\end{tabular}

a $1 \mathrm{~mm} \mathrm{Hg} \approx 0.133 \mathrm{kPa}$.

${ }^{*} P<0.05,{ }^{* *} P<0.02, * * * P<0.01$.

jects, and are also given for the entire employed male sample.

Considering the quadrant-term categorization of job strain (table 4), significant differences are observable in the blood pressure levels only for the systolic component, both clinical and ambulatory, among the normotensive subjects. The highest systolic blood pressure values were found in the high-strain group, followed by the passive, active and low-strain groups. The differences between the means in the extreme groups (ie, high strain versus low strain) were $4.3,2.8,3.4 \mathrm{~mm} \mathrm{Hg}(0.6,0.4$, $0.5 \mathrm{kPa}$ ) for the systolic CBP, 24-h ABP and work ABP, respectively. Similar patterns were detectable for the mean diastolic levels of the normotensives, but the differences were minimal [about $1 \mathrm{~mm} \mathrm{Hg}(0.1 \mathrm{kPa})$ be- tween the extremes] and not statistically significant. Among the mild hypertensive subjects, only relatively small fluctuations in the job-strain categories, in the absence of any consistent patterns, were present for both the systolic and diastolic blood pressure. On the other hand, for the entire sample, statistically significant differences in the mean systolic blood pressure, with higher values for the high-strain and passive subjects in contrast to the active and low-strain workers, were detectable only for the CBP.

When the tertile-term approach was adopted for the job-strain categorization (table 5), the reported findings for systolic blood pressure were confirmed for the normotensives. The mean differences between the highstrain and low-strain groups were generally greater for 
Table 5. Mean systolic and diastolic blood pressures (adjusted for age, education, overweight index and physical-activity index) of the normotensive $(\mathrm{N}=258)$ and mild hypertensive $(\mathrm{N}=79)$ men and the entire group $(\mathrm{N}=337)$ from the PAMELA general population sample according to the job-strain tertile-term category. (CBP = clinic blood pressure, $A B P=$ ambulatory blood pressure)

\begin{tabular}{|c|c|c|c|c|c|c|}
\hline \multirow[t]{2}{*}{ Job-strain category } & \multicolumn{2}{|c|}{$\mathrm{CBP}(\mathrm{mm} \mathrm{Hg})$} & \multicolumn{2}{|c|}{ 24-h ABP $\left(\mathrm{mm} \mathrm{Hg}^{\mathrm{a}}\right)$} & \multicolumn{2}{|c|}{ Work ABP $\left(\mathrm{mm} \mathrm{Hg}^{\mathrm{a}}\right)$} \\
\hline & Systolic & Diastolic & Systolic & Diastolic & Systolic & Diastolic \\
\hline \multicolumn{7}{|l|}{ High } \\
\hline $\begin{array}{l}\text { Normotensives } \\
\text { Mild hypertensives } \\
\text { Entire group }\end{array}$ & $\begin{array}{l}124.4 \\
141.5 \\
127.7\end{array}$ & $\begin{array}{l}80.2 \\
89.9 \\
82.5\end{array}$ & $\begin{array}{l}119.8 \\
125.0 \\
120.8\end{array}$ & $\begin{array}{l}74.3 \\
78.3 \\
75.3\end{array}$ & $\begin{array}{l}126.2 \\
131.7 \\
127.4\end{array}$ & $\begin{array}{l}80.4 \\
84.4 \\
81.3\end{array}$ \\
\hline \multicolumn{7}{|l|}{ Passive } \\
\hline $\begin{array}{l}\text { Normotensives } \\
\text { Mild hypertensives } \\
\text { Entire group }\end{array}$ & $\begin{array}{l}123.5 \\
137.8 \\
126.7\end{array}$ & $\begin{array}{l}80.5 \\
90.9 \\
82.8\end{array}$ & $\begin{array}{l}118.2 \\
118.9 \\
118.4\end{array}$ & $\begin{array}{l}73.9 \\
75.7 \\
74.3\end{array}$ & $\begin{array}{l}125.4 \\
126.1 \\
125.6\end{array}$ & $\begin{array}{l}80.7 \\
82.2 \\
81.1\end{array}$ \\
\hline \multicolumn{7}{|l|}{ Active } \\
\hline $\begin{array}{l}\text { Normotensives } \\
\text { Mild hypertensives } \\
\text { Entire group }\end{array}$ & $\begin{array}{l}120.5 \\
139.2 \\
125.2\end{array}$ & $\begin{array}{l}80.4 \\
93.1 \\
83.7\end{array}$ & $\begin{array}{l}117.7 \\
126.6 \\
119.8\end{array}$ & $\begin{array}{l}74.3 \\
80.3 \\
75.8\end{array}$ & $\begin{array}{l}123.7 \\
135.4 \\
126.4\end{array}$ & $\begin{array}{l}80.2 \\
87.7 \\
82.1\end{array}$ \\
\hline \multicolumn{7}{|l|}{ Low } \\
\hline $\begin{array}{l}\text { Normotensives } \\
\text { Mild hypertensives } \\
\text { Entire group }\end{array}$ & $\begin{array}{l}119.7 \\
138.7 \\
123.1\end{array}$ & $\begin{array}{l}79.0 \\
91.9 \\
81.7\end{array}$ & $\begin{array}{l}115.8 \\
128.0 \\
118.0\end{array}$ & $\begin{array}{l}72.6 \\
79.3 \\
74.0\end{array}$ & $\begin{array}{l}122.0 \\
136.3 \\
124.7\end{array}$ & $\begin{array}{l}78.1 \\
86.1 \\
79.8\end{array}$ \\
\hline \multicolumn{7}{|l|}{$F p$} \\
\hline $\begin{array}{l}\text { Normotensives } \\
\text { Mild hypertensives } \\
\text { Entire group }\end{array}$ & $\begin{array}{l}4.22^{\star \star \star} \\
0.51 \\
2.52\end{array}$ & $\begin{array}{l}0.71 \\
1.07 \\
1.1\end{array}$ & $\begin{array}{l}2.94^{*} \\
4.12^{\star * *} \\
2.06\end{array}$ & $\begin{array}{l}1.28 \\
2.78^{\star} \\
2.08\end{array}$ & $\begin{array}{l}3.09^{*} \\
4.24^{\star * \star} \\
1.24\end{array}$ & $\begin{array}{l}1.99 \\
2.72^{*} \\
1.79\end{array}$ \\
\hline
\end{tabular}

a $1 \mathrm{~mm} \mathrm{Hg} \approx 0.133 \mathrm{kPa}$.

${ }^{*} P<0.05,{ }^{\star *} P<0.01$.

the ABP $[4.0 \mathrm{~mm} \mathrm{Hg}(0.5 \mathrm{kPa})$ for the $24-\mathrm{h} \mathrm{ABP}$ and 4.2 $\mathrm{mm} \mathrm{Hg}(0.6 \mathrm{kPa})$ for the work $\mathrm{ABP}]$. In addition, statistically significant differences emerged for the mild hypertensives for both the systolic and diastolic measurements of the 24-h ABP and work ABP values. However, the highest systolic values were observed in the low-strain group, followed by the active, high-strain, and, finally, the passive groups, the last with particularly low values. The differences between the extremes (low-strain versus passive) were 9.1 and $10.2 \mathrm{~mm} \mathrm{Hg}(1.2$ and $1.4 \mathrm{kPa}$ ) for the 24-h ABP and work ABP measurements, respectively. A statistically significant lower value was found for the diastolic ABP of the passive group for the 24-h ABP and work $\mathrm{ABP}$ measurements.

No relevant differences in the mean blood pressure values (neither systolic nor diastolic) were observable when the entire sample was considered.

In figure 2, multivariable-adjusted values for the mean ABP, during worktime, leisure time, and nighttime are reported for the tertile-term job-strain categories for the normotensive and mild hypertensive subjects, separately. Similar patterns, although attenuated, were detected when the quadrant-term approach (data not reported) was used. Gradual and steady declines in the mean blood pressure values were observable for both the systolic and the diastolic components and for all the jobstrain categories from work to leisure time, and even greater declines were seen from leisure time to nighttime. Moreover for the systolic component, the ranking of the mean blood pressure values of the job-strain categories remained stable for the entire circadian period. This finding was particularly evident for the lower values of the passive job category among the mild hypertensives. On the other hand, for the diastolic component, the detected differences during work progressively weakened during leisure time and disappeared at night.

Finally, tables 6 and 7 present the disparities in blood pressure (CBP minus 24-h ABP and CBP minus work $\mathrm{ABP}$ mean differences) between the normotensive and mild hypertensive subjects with respect to the systolic and diastolic values of the tertile-term job-strain categories. The analysis for the quadrant-term categories has not been included because the results were analogous and less significant. Mild hypertensives showed consistent and statistically significant higher disparities than the normotensive subjects for both the systolic and diastolic blood pressures. The effect of the regression on the mean should be taken into account, but it cannot entirely explain the observed differences. It is notable that negative values were present only for normotensive subjects and for the CBP versus the work ABP systolic blood pressures. Statistically significant differences between the job-strain categories (with higher values in the passive group) were found for the systolic disparities (table 6), but not for the diastolic ones (table 7). Moreover, a statistically significant interaction effect was detected for the model containing the difference between the systolic CBP and the work ABP as a dependent variable. 
NORMOTENSIVES
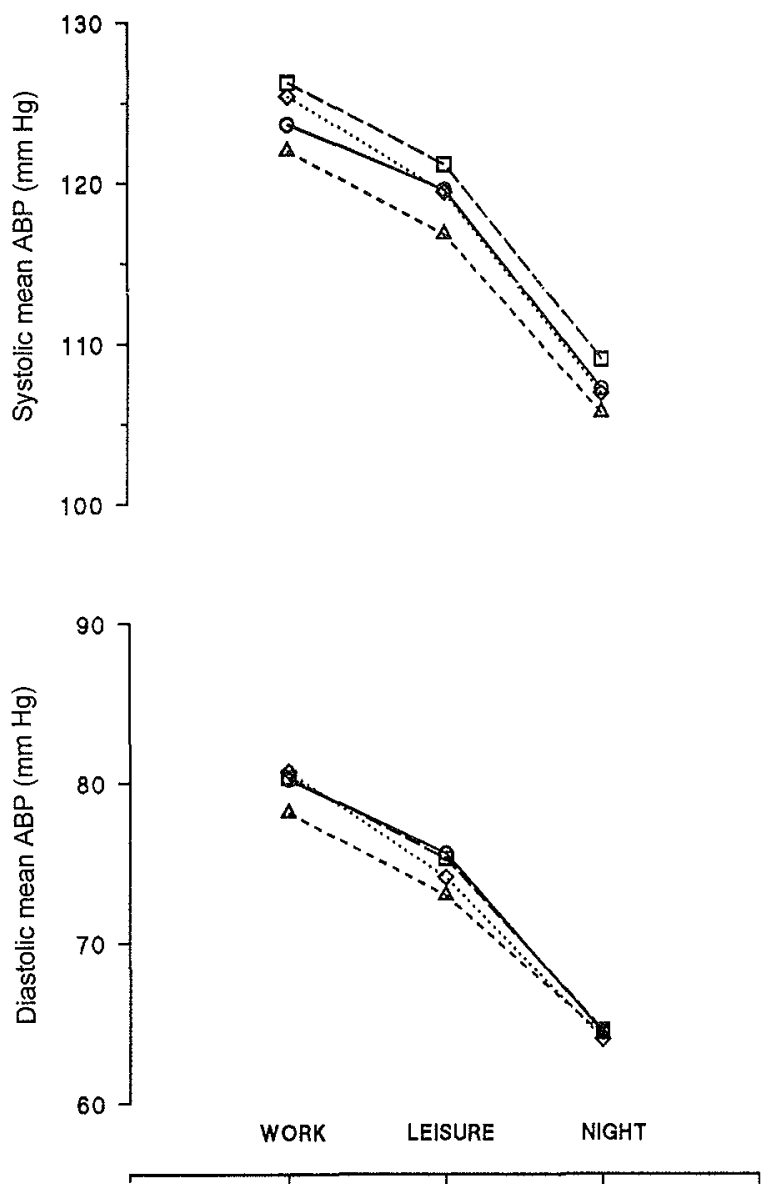

BORDERLINE HYPERTENSIVES
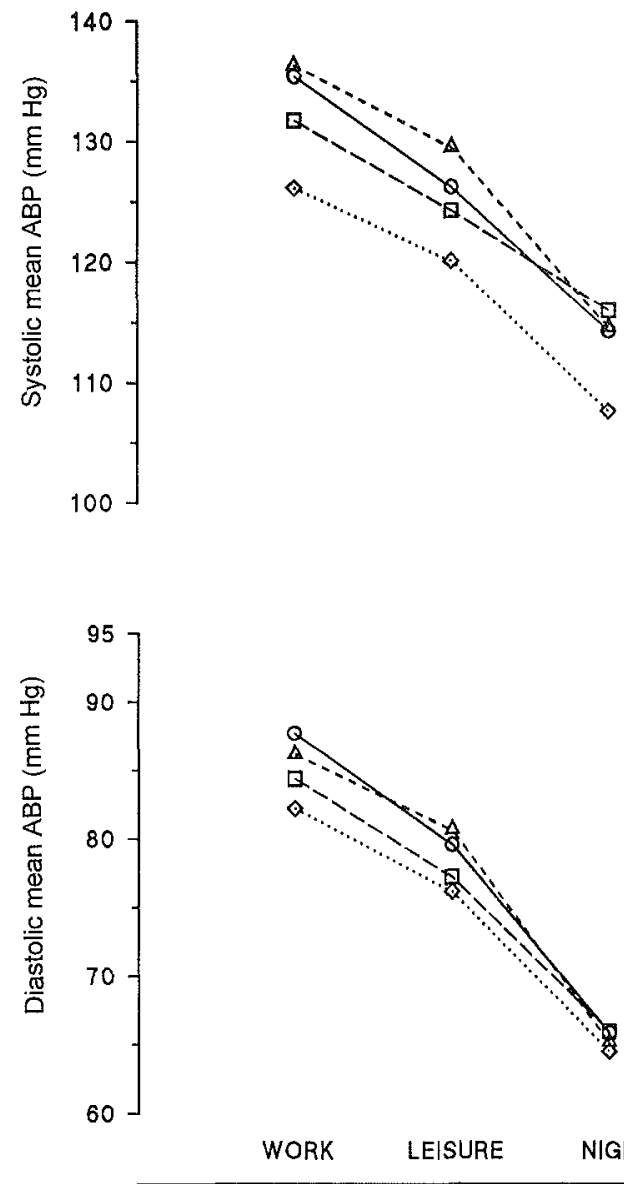

Figure 2. Mean ambulatory blood pressure (ABP) values (adjusted for age, educational class, overweight index and physical-activity index) of the job-strain categories (tertile score), during work, leisure time and night. Normotensive and mildly hypertensive working men extracted from the PAMELA general population sample. ( $O=$ active, $\square=$ high, $\Delta=$ low, $\diamond=$ passive)

This effect was primarily attributable to the higher mean value $[12.9 \mathrm{~mm} \mathrm{Hg}(1.7 \mathrm{kPa})]$ observed for the passive mild hypertensives (table 6).

\section{Discussion}

The primary intent of the psychosocial substudy within the WHO MONICA project was to promote consistent and controlled methods to collect subjective and biological information in epidemiologic studies of coronary heart disease. This methodological effort is particularly important because most flaws in the research on the relationship between psychosocial factors and disease risk also arise from the use of arbitrary and unreliable measurements (46).

The standard edition of the Karasek questionnaire, adopted by MOPSY and by this study, has been widely used and the quadrant term is the reference scoring sys- tem of most research in which job strain has been evaluated in the absence of the contribution of the social support dimension. When the distribution of (quadrant) job-strain categories in the pooled data of the MONICA and PAMELA surveys was examined across the five occupational groups reported in the Methods section, it was found that the high-strain and passive categories tended to increase (from $38 \%$ to $76 \%$ ) as the occupational level decreased; the opposite was true for the active and low-strain categories (from $62 \%$ to $23 \%$ ) (47). On one hand, these results confirm that even in general population samples of Italy, the adopted job-strain scale validly estimates a worsening job perception in objectively worsening job conditions and, on the other hand, indicates that, in such samples, aggregated analysis is more sensitive to job latitude than to psychological demand.

As noted in the Introduction section and documented by a recent extensive review (48), previous studies carried out on population-based samples and using standard 
Table 6. Differences in the mean systolic blood pressures (adjusted for age, education, overweight index and physical-activity index) of the normotensive $(N=258)$ and mild hypertensive $(N=79)$ men and the entire group $(N=337)$ from the PAMELA general population sample according to the job-strain tertile-term category. $(\mathrm{CBP}=$ clinic blood pressure, $\mathrm{ABP}=$ ambulatory blood pressure)

\begin{tabular}{lcc}
\hline Job-strain category & $\begin{array}{r}\text { CBP minus } \\
\text { 24-h ABPa } \\
(\mathrm{mm} \mathrm{Hg})\end{array}$ & $\begin{array}{c}\text { CBP minus } \\
\text { work ABPb } \\
(\mathrm{mm} \mathrm{Hg})\end{array}$ \\
\hline High & & \\
Normotensives & 4.9 & -1.7 \\
Mild hypertensives & 13.8 & 7.1 \\
Entire group & 9.3 & 2.7 \\
Passive & & \\
Normotensives & 5.2 & -1.9 \\
Mild hypertensives & 19.5 & 12.9 \\
Entire group & 12.3 & 5.5 \\
Active & & \\
Normotensives & 3.2 & -2.7 \\
Mild hypertensives & 13.0 & 4.5 \\
Entire group & 8.1 & 0.9 \\
Low & & \\
Normotensives & & -1.7 \\
Mild hypertensives & 4.2 & 4.9 \\
Entire group & 12.8 & 1.4 \\
Overall & 8.5 & \\
Normotensives & & -2.1 \\
Mild hypertensives & 4.4 &.. \\
Entire group & 14.8 &.. \\
\hline
\end{tabular}

a Main effect of job strain: $F=3.37, P<0.02$; main effect of the hypertension classes: $F=87.05, P<0.01$; interaction term of job strain and hypertension: $F=1.52, P=0.21$

- Main effect of job strain: $F=3.34, P<0.02$; main effect of the hypertension classes: $F=61.5, P<0.01$; interaction term of job strain and hypertension: $\mathrm{F}=2.63, \mathrm{P}=0.05$

. $1 \mathrm{~mm} \mathrm{Hg} \approx 0.133 \mathrm{kPa}$

devices did not find convincing associations between job strain and blood pressure. On the other hand, the positive results yielded by $\mathrm{ABP}$ measurements were obtained from selected samples drawn from a small group of factories or on the basis of blood pressure levels (ie, borderline and mild hypertensive subjects). For these reasons the impact of their findings can hardly be extended to entire working populations.

Our study is the first in which $\mathrm{CBP}$ and $\mathrm{ABP}$ devices were used to assess the relationship between perceived job stress and blood pressure levels in an employed male sample randomly selected from the general population. The participation rate of $69.5 \%$ is acceptable for a population-based survey, especially when the nonrespondents do not show any significant differences in sociodemographic characteristics. The number of missing values was very small, only $4 \%$ of the employed sample. Possible selection biases attributable to the restriction produced when the tertile-term categorization was adopted can be ruled out because the results were not in contrast to the ones obtained with the quadrant term. Finally, the observed blood pressure values of the job-strain categories were analyzed separately for the normotensive and
Table 7. Differences in the mean diastolic blood pressures (adjusted for age, education, overweight index and physical-activity index) of the normotensive $(\mathrm{N}=258)$ and mild hypertensive $(\mathrm{N}=79)$ men and the entire group $(\mathrm{N}=337)$ from the PAMELA general population sample according to the job-strain tertile-term category. $(C B P=$ clinic blood pressure, $A B P=$ ambulatory blood pressure)

\begin{tabular}{|c|c|c|}
\hline Job-strain category & $\begin{array}{l}\text { CBP minus } \\
24-h \mathrm{ABPa}^{-} \\
(\mathrm{mm} \mathrm{Hg})\end{array}$ & $\begin{array}{l}\text { CBP minus } \\
\text { work } \mathrm{ABP}^{\mathrm{b}} \\
\text { (mm } \mathrm{Hg}^{\mathrm{c}} \text { ) }\end{array}$ \\
\hline \multicolumn{3}{|l|}{ High } \\
\hline $\begin{array}{l}\text { Normotensives } \\
\text { Mild hypertensives } \\
\text { Entire group }\end{array}$ & $\begin{array}{r}5.9 \\
11.8 \\
8.8\end{array}$ & $\begin{array}{r}-0.2 \\
5.4 \\
2.6\end{array}$ \\
\hline \multicolumn{3}{|l|}{ Passive } \\
\hline $\begin{array}{l}\text { Normotensives } \\
\text { Mild hypertensives } \\
\text { Entire group }\end{array}$ & $\begin{array}{r}6.4 \\
15.3 \\
10.9\end{array}$ & $\begin{array}{r}-0.3 \\
9.0 \\
4.3\end{array}$ \\
\hline \multicolumn{3}{|l|}{ Active } \\
\hline $\begin{array}{l}\text { Normotensives } \\
\text { Mild hypertensives } \\
\text { Entire group }\end{array}$ & $\begin{array}{r}5.9 \\
13.5 \\
9.7\end{array}$ & $\begin{array}{r}-0.1 \\
6.4 \\
3.2\end{array}$ \\
\hline \multicolumn{3}{|l|}{ Low } \\
\hline $\begin{array}{l}\text { Normotensives } \\
\text { Mild hypertensives } \\
\text { Entire group }\end{array}$ & $\begin{array}{r}6.5 \\
14.0 \\
10.2\end{array}$ & $\begin{array}{r}-1.0 \\
6.9 \\
3.9\end{array}$ \\
\hline \multicolumn{3}{|l|}{ Overall } \\
\hline $\begin{array}{l}\text { Normotensives } \\
\text { Mild hypertensives } \\
\text { Entire group }\end{array}$ & $\begin{array}{r}6.2 \\
13.6 \\
. .\end{array}$ & $\begin{array}{r}-0.1 \\
6.7 \\
. .\end{array}$ \\
\hline \multicolumn{3}{|c|}{$\begin{array}{l}\text { Main effect of job strain: } F=1.56, P<0.20 \text {; main effect of the hyperten- } \\
\text { sion classes: } F=105.78, P<0.01 \text {; interaction term of job strain and hy- } \\
\text { pertension: } F=0.80, P=0.49 \text {. } \\
\text { Main effect of job strain: } F=0.96, P<0.41 \text {; main effect of the hyperten- } \\
\text { sion classes: } F=71.2, P<0.01 \text {; interaction term of job strain and hyper- } \\
\text { tension: } F=1.20, P=0.31 \text {. } \\
\text { - } 1 \mathrm{~mm} \mathrm{Hg} \approx 0.133 \mathrm{kPa} \text {. }\end{array}$} \\
\hline
\end{tabular}

mild hypertensive subjects. Since no significant differences were detected in the proportion of mild hypertensives in the job-strain groups (both for the quadrant-term and the tertile-term approaches), it is possible to exclude differential selection processes due to the adopted cutoff points used to classify mild hypertension.

In this cross-sectional evaluation, normotensive working men in the high-strain group showed the highest mean systolic blood pressure, followed by the mean in the passive, active and low-strain categories. As already indicated, the observed effects were small (24), but they were consistent because they persisted also when ambulatory monitoring devices which reduce blood pressure variability $(45,46)$ were used. They increased from the quadrant-term to the proposed tertile-term scoring approach. We could not find similar significant associations between job strain and diastolic blood pressure among the employed normotensive men, even if the CBP and $A B P$ values tended to be lower as work stress perception declined.

The results obtained for the mild hypertensive subjects differed. No significant variations in the clinical and ambulatory systolic or diastolic blood pressures were 
observable with the quadrant-term classification of job strain. When the contrasts were enhanced by the tertileterm score, highly significant differences were found for the systolic and diastolic values, when 24-h ABP and work ABP measurements were considered. The direction of such differences indicates that the lower control categories (high strain and, in particular, passive) showed lower blood pressure values than the higher control categories (active and low strain). The analysis of blood pressure disparities revealed that passive persons show higher values for the systolic component; therefore, in our sample, these persons may have been more prone to alarm reactions. On the other hand, in our study, there was no clear evidence of higher blood pressure values among the high-strain men in the mild hypertensive group. These findings may be the consequence of some unforeseen selection phenomena. Alternatively they may be explained by the interpretation that attributes alexitimic and denial tendencies to subjects predisposed to hypertension as a psychosomatic solution to their anxiety trait $(17,32,49,50)$. Theorell et al (24) obtained opposite results for borderline hypertensives (ie, higher diastolic blood pressure values in the high-strain category), but some methodological differences in assessing job strain should be acknowledged (ie, direct method in the present study and indirect method, based on job-title categorization, in the Swedish report). We did not observe a significantly different distribution of mild hypertensives among the occupational classes, and, even if they had had a systematically altered perception of strain, they could not have therefore contributed to the previously described marked differences in job strain among the occupational classes.

The size of the observed differences for the work ABP blood pressure levels of the job-strain groups dropped for both the normotensive and mild hypertensive subjects when the leisure time and nighttime ambulatory blood pressure means were taken into consideration. The only exception occurred for the passive group, in which the lower blood pressure values were maintained during the whole circadian cycle. On the whole, our ambulatory data only partially confirm the so-called "carry-over effect" (28), in which increases in blood pressure among strained or alexitimic workers are prolonged during leisure time and (less) nighttime.

Blood pressure seems to be a parameter of choice in epidemiologic evaluations of the biological counterpart of strain or stress phenomena induced by work and life conditions. Blood pressure is continuously, positively, and independently associated with serious outcomes such as stroke and coronary events for most persons, whether they are conventionally normotensive or hypertensive (51). The numerous confirmations of the tendency of blood pressure to stabilize at increased levels in relation to different objectively or subjectively perceived job- strain conditions indicate a massive risk phenomenon, the study of which has merely begun. Our results corroborate the heuristic value of the job demand-decision latitude model across cultures and randomly selected working samples.

\section{Acknowledgments}

The research was supported by a grant from the Italian National Research Council (CNR) within the framework of the FATMA project (contract 91.00120.PF4).

The secretarial and editing contributions of Ms Della Chambless are gratefully acknowledged.

\section{References}

1. Kristensen TS. Cardiovascular diseases and the work environment: a critical review of the epidemiologic literature on nonchemical factors [review]. Scand J Work Environ Health 1989; 15:165-79.

2. Karasek RA, Theorell T. Healthy work. New York (NY): Basic Books, 1990.

3. Johnson JV. The significance of social and collective dimensions of the work environment for human health and wellbeing. In: Enander A, Gustavsson B, Karlsson J, Starrin B, editors. Work and welfare: papers from the Second Karlstad Symposium on Work. Karlstad (Sweden): University of Karlstad, 1991:31-45.

4. Karasek RA. Job demands, job decision latitude and mental strain: implication for job redesign. Adm Sci Q 1979;24:285307.

5. Theorell T. The psychosocial environment, stress and coronary heart disease. In: Marmot M, Elliot P, editors. Coronary heart disease epidemiology. Oxford: Oxford University Press, 1992:256-73.

6. Kristensen TS. The demand control support model-methodological challenges for future research. Stress Med 1995;11: $17-26$.

7. Karasek RA, Baker D, Marxer F, Ahlbom A, Theorell T. Job decision latitude, job demands and cardiovascular disease: a prospective study of Swedish men. Am J Public Health 1981; 71:694-705.

8. Alfredsson L, Spetz CL, Theorell T. Type of occupation and near future hospitalization for myocardial infarction and some other diagnosis. Int J Epidemiol 1985;14:378—88.

9. Karasek RA, Theorell T, Schwartz JE, Schnall PL, Pieper CF. Job characteristics in relation to the prevalence of myocardial infarction in the US Health Examination Survey (HES) and the Health and Nutrition Examination Survey (HANES). Am J Public Health 1988;78:910-18.

10. Haan MN. Job strain and ischaemic heart disease: an epidemiologic study of metal workers. Ann Clin Res 1988;20:143-5.

11. Johnson JV, Hall EM, Theorell T. Combined effects of job strain and social isolation on cardiovascular disease morbidity and mortality in a random sample of the Swedish male working population. Scand J Work Environ Health 1989;15:271— 9. 
12. Hammar H, Alfredsson L, Theorell T. Job characteristics and the incidence of myocardial infarction. Int J Epidemiol 1994; 23:277-84.

13. Reed DM, LaCroix AZ, Karasek RA, Miller D, MacLean CA. Occupational strain and incidence of coronary heart disease. Am J Epidemiol 1989;129:495 - 502.

14. Alterman T, Shekelle RB, Vernon SW, Burau KD. Decision latitude, psychologic demand, job strain and coronary heart disease. Am J Epidemiol 1994;139:620-7.

15. Hiatky MA, Lam LC, Clappchanning NE, Williams RB, Pryor $\mathrm{DB}$, Califf KM, et al, Job strain and the prevalence and the outcome of coronary artery disease. Circulation 1995;92: $327-33$.

16. Matthews KA, Cottington EM, Talbott E, Kuller LH, Siegel JM. Stressful work conditions and diastolic blood pressure among blue collar factory workers. Am J Epidemiol 1987;126: $280-91$.

17. Winkleby MA, Ragland DR, Syme SL. Self reported stressor and hypertension: evidence of an inverse association. Am J Epidemiol 1988;127:124—34.

18. Pieper C, Lacroix AZ, Karasek RA. The relation of psychosocial dimensions of work with coronary heart disease factors: a meta-analysis of five Unite States data bases. Am J Epidemiol 1989;129:483-94.

19. Netterstrom B, Kristensen TS, Damsgaard MT, Olsen O, Sjol A. Job strain and cardiovascular risk factors: a cross sectional study of employed Danish men and women. Br J Ind Med 1991;48:684-9.

20. Chapman A, Mandryk JA, Frommer MS, Edye BV, Fergusson DA. Chronic work stress and blood pressure among Australian government employees. Scand J Work Environ Health 1990; $16: 258-69$

21. Albright CL, Winkleby MA, Ragland DR, Fisher J, Syme SL. Job strain and prevalence of hypertension in a biracial population of urban bus drivers. Am J Public Health 1992;82:984 9.

22. Green KL, Johnson JV. The effects of psychosocial work organization on pattern of cigarette smoking among male chemical plant employees. Am J Public Health 1990;80: $1368-71$.

23. Schnall PL, Pieper C, Schwartz JE, Karasek RA, Schlussel Y, Devereux RB, et al. The relationship between job strain, workplace diastolic blood pressure and left ventricular mass index: results of a case-control study. JAMA 1990;263:1929 —35.

24. Theorell T, de Faire U, Johnson J, Hall E, Perski A, Stewart W. Job strain and ambulatory blood pressure profiles. Scand J Work Environ Health 1991;17:380-5.

25. Van Egeren LF. The relationship between job strain and blood pressure at work, at home and during sleep. Psychosom Med 1992;54:337-43.

26. Schnall PL, Schwartz JE, Landsbergis PA, Warren K, TG Pickering. Relation between job strain, alcohol and ambulatory blood pressure. Hypertension 1992;19:488-94.

27. Theorell T, Ahlberg-Hulten G, Jodko M, Sigala F, de la Torre $B$. Influence of job strain and emotion on blood pressure in female hospital personnel during workhours. Scand J Work Environ Health 1993;19:313-8.

28. Schnall PL, Schwartz JE, Landsbergis PA, Warren K, Pickering TG. The relationship between "job strain" and change in ambulatory blood pressure: results of a prospective cohort study. Presented at the American Public Health Association Congress, San Francisco CA, October 1993.

29. Landsbergis PA, Schnall PL, Warren K, Pickering TG, Schwartz JE. Association between ambulatory blood pressure and alternative formulation of job strain. Scand J Work Environ Health 1994;20:349-63.

30. Theorell T, Knox S, Svensson J, Waller D. Blood pressure variations during a working day at age 28: effects of different types of work and blood pressure level at age 18. J Hum Stress 1985;11:36-41.

31. Härenstam $\mathrm{AB}$, Theorell TPG. Work condition and urinary excretion of catecholamines - a study of prison staff in Sweden. Scand J Work Environ Health 1988;14:257-64.

32. Theorell T, Perski A, Åkerstedt T, Sigala F Ahlberg-Hultén G, Svensson $\mathbf{J}$, et al. Changes in job strain in relation to changes in physiological states: a longitudinal study. Scand J Work Environ Health 1988;14:189-96.

33. Light KC, Turner JR, Hinderliter AL. Job strain and ambulatory work blood pressure in healthy young men and women. Hypertension 1992;20:214-8.

34. Blumenthal JA, Thyrum ET, Siegel WC. Contribution of jobstrain, job status and marital status to laboratory and ambulatory blood pressure in patients with mild hypertension. J Psychosom Res 1995;39:133 - 44.

35. World Health Organization (WHO) Regional Office for Europe. Consultation on psychosocial determinants of cardiovascular diseases. Copenhagen: WHO Regional Office for Europe, 1984. Draft $1752 \mathrm{H}$.

36. World Health Organization (WHO) MONICA Project Principal Investigators. The World Health Organization MONICA project (MONItoring trends and determinants in CArdiovascular disease): a major international collaboration. J Clin Epidemiol 1988;41:105-14.

37. Cesana GC, Poncato E, Duzioni F, Bocchini O, Grieco A. Indagine pilota sull'affidabilità di un questionario per lo studio dei fattori psico-socio-occupazionali in relazione all'insorgenza di coronaropatia [Pilot work on the reliability of a general questionnaire for the study of psychosocial and occupational factors related to cardiovascular disease]. Arch Sci Lav 1987;3:151-60.

38. Cesana GC, De Vito G, Ferrario M, Libretti A, Mancia G, Zanchetti A, et al. Ambulatory blood pressure mormalcy: the PAMELA Study. J Hypertension 1991;9:S17—S23.

39. Ferrario M, Sega R, Cesana GC. Lessons from the MONICA Study in Northern Italy. J Hypertension 1991;9:S7 - S14.

40. World Health Organization (WHO) Regional Office for Europe. MONICA psychosocial optional study: MOPSY suggested measurement instruments. Copenhagen: WHO Regional Office for Europe, 1989. EUR/ICP/NCD 011.

41. Baecke JAH, Burema MS. A short questionnaire for the measurement of habitual physical activity in epidemiological studies. Am J Clin Nutr 1982;36:936 42.

42. World Health Organization (WHO) MONICA Project Principal Investigators. MONICA manual: version 1.1. Geneva: WHO CVD Unit, 1987.

43. Mancia G, Sega R, Bravi C, De Vito G, Valagussa F, Cesana $\mathrm{GC}$, et al. Ambulatory blood pressure normality: results from the PAMELA study. J Hypertension 1995;13:1377-90.

44. SAS. GLM Procedure. In: SAS/STAT user's guide. 6.03 ed. Cary (NC): SAS Institute Inc, 1991:549-641.

45. Pickering TG, Gerin WA. Ambulatory blood pressure monitoring and cardiovascular reactivity testing for the evaluation of the role of psychosocial factors and prognosis in hypertensive patients. Am Heart J 1988;116:665-72.

46. Cesana GC. Physiological reactions in epidemiological studies. Copenhagen: World Health Organization, Regional Office for Europe, 1993:283-301.

47. Cesana GC, Ferrario M, De Vito G, Grieco A. Evaluation of 
socio-economic status in epidemiological surveys: proposals from the Area Brianza MONICA project. Med Lav 1995;86: $16-26$.

48. Schnall PL, Landsbergis PA. Job strain and cardiovascular disease. Annu Rev Public Health 1994;15:381-411.

49. Jorgensen RS, Houston BK. Family history of hypertension, personality patterns and cardiovascular reactivity to stress. Psychosom Med 1986:48:102-17.
50. Theorell T. Family history of hypertension - an individual trait interacting with spontaneously occurring job stressors. Scand J Work Environ Health 1990;16 suppl 1:74-9.

51. Stamler J, Stamler R, Neaton JD. Blood pressure, systolic and diastolic, and cardiovascular risks - United States population data. Arch Int Med 1993;153:598—615.

Received for publication: 6 October 1995 